\title{
Minimization of the Lifecycle Cost of a Rotary Heat Exchanger Used in Building Ventilation Systems in Cold Climates
}

\author{
Ignas Sokolnikas ${ }^{1}$ - Kęstutis Čiuprinskas2,* - Jolanta Čiuprinskienè2 \\ ${ }^{1}$ Salda UAB, Lithuania \\ 2 Vilnius Gediminas Technical University, Lithuania
}

This article presents an analysis of rotary heat exchangers (RHE) used as heat recovery units in building ventilation systems in cold climates. Usually, heat exchangers with the highest heat transfer efficiency are the preferable option for this purpose. However, such exchangers usually have the highest media pressure drop, thus requiring the highest amount of energy for media transportation. In this study, the problem is solved by analysing the lifecycle cost (LCC) of the RHE including both the recovered heat and the electricity consumed in the fans of the air handling unit (AHU). The purpose of the investigation was to determine the optimal set of geometrical characteristics such as the exchanger's length, foil thickness, the height and width of the air channel. Two hundred and seventy different combinations were examined using analytical dependencies and ANSYS simulations. The results are compared with experimental data obtained earlier at the KOMFOVENT laboratory. The results show that the best overall energy efficiency is obtained in heat exchangers that do not offer the best heat recovery efficiency, and LCC differences in the same climatic and economic conditions can go as high as $31 \%$, mainly due to the geometrical parameters of the heat exchanger.

Keywords: rotary heat exchanger, heat recovery, ventilation system, temperature efficiency, pressure loss, ANSYS, lifecycle cost

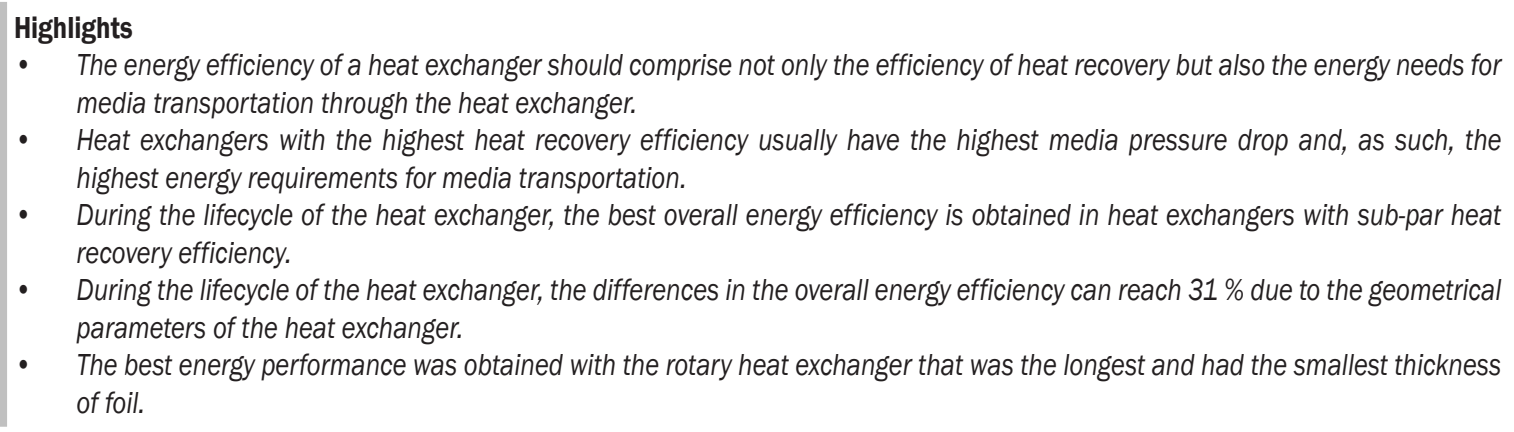

\section{INTRODUCTION}

Nowadays, mechanical ventilation systems are an indispensable part of building engineering systems. Ventilation systems consume about $10 \%$ of energy in commercial buildings [1]. Ventilation systems also increase heating and cooling system operating costs, which constitute $25 \%$ and $9 \%$ of building energy, respectively [1]. The main element of a ventilation system that saves the majority of thermal energy is the heat exchanger located in the air handling unit (AHU). Rotary and plate heat exchangers are most commonly used for this purpose.

In Lithuania, as well as in other cold climate countries, rotary heat exchangers (RHE) are the preferred type due to lower frosting in low outdoor temperatures, humidity recovery, compactness, and no drainage requirement. Rotary heat exchangers usually are classified into three types: condensation, enthalpy, and sorption heat exchangers. In this research, a condensation-type rotary heat exchanger is investigated.

The initial aim of the literature review was to discover some constructional recommendations in pursuance of maximal overall energy efficiency of the RHE, including heat transfer efficiency and the energy required to overcome the aerodynamic resistance of the RHE. As expected, no such specific recommendations were found. The majority of studies focus on the heat and moisture transfer efficiency of heat exchangers and ignore the pressure loss. The primary goal of research [2] was to develop a mathematical and numerical model to predict the energy wheel's effectiveness and to take into account the condensation and evaporation processes. Paper [3] presents the modelling results of the recovery unit working in real conditions with regard to changes in temperature, air velocity, and rotor speed. In [4], the heat and mass transfer in a desiccant wheel was modelled into a set of linear differential equations under the linearization assumptions on the temperature 
and humidity profiles and the psychrometric relation. In [5], the optimum operational conditions of the rotary regenerator were obtained using genetic algorithm optimization technique subject to a list of constraints. The objective function in the optimization technique was the thermal effectiveness, while the design parameters (decision variables, the optimum operating conditions of the rotary regenerator were obtained using a genetic algorithm. The objective function in the optimization technique was the thermal effectiveness, while the design parameters (decision variables) were volumetric flow rates of cold and hot air streams, matrix rotational speed, and the exchanger's frontal area (heat transfer surface area). The purpose of the study in [6] was to propose a mathematical model for the heat and mass transfer characteristics (moisture removal capacity and the moisture removal regeneration) of a zeolite-coated heat exchanger. The lack of such recommendations has also been observed by RHE manufacturers [7]. In a study of geometrical parameters on heat and mass transfer processes [8], pressure drop over the RHE is used as an indicator of the frosting progress only; energy consumed by fans is not included in the evaluation. In some research projects, energy consumed in AHU fans is taken into account [9] and [10] and even is referred to as a "significant part" of the total primary energy used [10]; however, it still omitted from the overall energy efficiency evaluation. AHU fan energy is included in power usage effectiveness (PUE) used as an energy efficiency indicator of data centre facilities, and the study in [11] is quite informative in this context; however, it only gives a distinct presentation of electrical power, but not energy use, and no energy increase due to the use of the RHE is given.

Regardless of the different field of application, one of the best formulations of the problem is given in an RHE optimization study [12]. Recovered heat and energy used in fans are defined as "conflicting objectives", and a solution is given as a Pareto optimum. In the field of air conditioning, the connection between heat transfer efficiency and pressure loss is probably given the most attention indepth in two studies [13] and [14]. In [13], the optimal geometrical parameters of the RHE are determined using the Pareto front concept; in [14] the boundaries of a more generalized porosity factor are defined for the typical operational conditions of the RHE. Unfortunately, neither of the studies analyse the ratio between the recovered heat and the consumed electrical energy.
Simplified analytical models are used in most of the sources reviewed, though it is well known that solving non-linear partial differential equations is generally needed in the case of heat and mass transfer. In [4], the advantages of analytical versus computational methods are presented, and an analytical solution using the linearization of differential equations of heat and mass transfer in a desiccant wheel is proposed. In contrast, some authors state that it is impossible to accurately calculate the temperature efficiency of an RHE by applying the analytical method, because the process of heat exchange is not stationary [15] and [16]. The application of numerical models produces results that are closer to experimental results yet are not always very reliable [2] and [17].

As expected, there is no clear dependence of temperature efficiency or pressure loss on one parameter. Due to the aforementioned reasons, there are no distinct guidelines for designing an RHE, or they are too abstract. Although some sources [13], [14] and [18] suggest that the RHE with the highest temperature efficiency ratio would not be expected to be the most energy-efficient due to the high-pressure losses of such a heat exchanger. Therefore, this research focuses on the optimal ratio of temperature efficiency to pressure losses.

The objective of this research was to find the optimal set of geometrical RHE parameters, taking into consideration the heat recovered by the heat exchanger and the energy used for air transportation through the exchanger itself (i.e., the difference in the amount of electricity used in the fans with and without the RHE). These energy amounts are assessed during the lifecycle of the RHE. Additional outcomes from this research are the range of variation of lifecycle costs (LCC) and the possibility to use the results obtained in formulating the selection criteria of the RHE.

\section{METHODS}

The computational fluid dynamics (CFD) model was adopted to determine the main variable of the problem: the temperature efficiency ratio of the RHE. The pressure drop was initially calculated using the same CFD model, which was later replaced with an analytical model due to its shorter calculation time. The CFD and analytical calculation results were validated by experimental tests results. The total amount of heat recovered, electricity consumed as well as energy and materials costs, were defined for Lithuanian weather and economic conditions. 
The set of the most significant parameters, such as the foil wave height and wavelength, the length of the RHE, the air velocity through the RHE, the foil thickness and the rotational speed of the RHE was determined on the basis of the literature review.

\subsection{Geometrical Model}

Constructively, an RHE is a drum (cylinder) of aluminium foil arranged in concentric rings. Both in the CFD model and in the experimental tests, the wave height and the wavelength of the RHE are determined using the Eurovent certification methodology [7]. The wavelength (b) was calculated using Eq. (1); the measurement scheme is shown in Fig. 1.

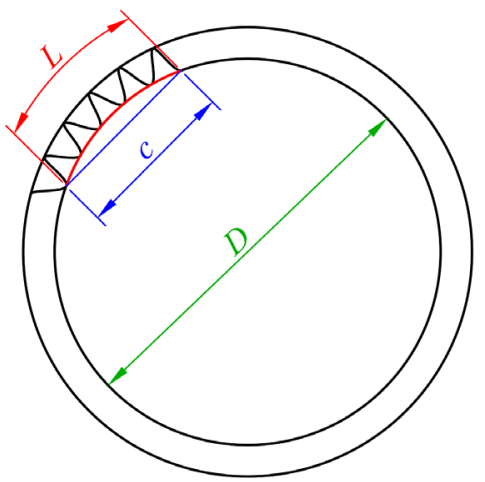

Fig. 1. Measuring the wavelength of the rotary heat exchanger

$$
b=\frac{D \cdot \arcsin (c / D)}{n},
$$

where $b$ is the calculated wavelength; $D$ is the diameter of the rotor $[\mathrm{mm}] ; c$ is the length of the measured segment $[\mathrm{mm}] ; n$ is the number of the waves in the measured segment.

The wave height was calculated by measuring the height of 10 to 20 waves, which was then divided by the number of waves. The wave height is shown below (Fig. 2):

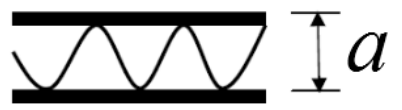

Fig. 2. Measuring the wave height (a) of the rotary heat exchanger

The temperature efficiency of the rotary heat exchanger was calculated using Eq. (2) [7]:

$$
\eta_{t}=\frac{t_{22}-t_{21}}{t_{11}-t_{21}}
$$

where $t_{22}$ is the temperature of the supplied air $\left[{ }^{\circ} \mathrm{C}\right]$; $t_{21}$ is the outdoor air temperature $\left[{ }^{\circ} \mathrm{C}\right] ; t_{11}$ is the indoor air temperature $\left[{ }^{\circ} \mathrm{C}\right]$.

\subsection{CFD Model}

The temperature efficiency of the RHE is determined using the ANSYS FLUENT 18.0 finite volume-based software [19]. The CFD model of an RHE consists of the RHE itself and four airflow sections. The RHE model is divided into a finite volume network consisting of 2,039 nodes and 8,087 finite volumes. The finite volume network is built from tetrahedrons. The model and the finite volume network thereof are shown in Fig. 3.

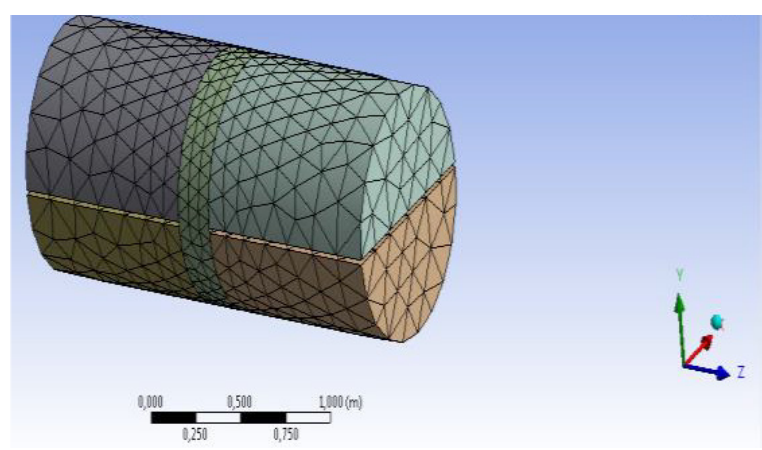

Fig. 3. The finite volume network of the rotary heat exchanger model

To describe the conditions of the problem, the $k$-epsilon viscosity model is selected. The change of the physical parameters of air over time is described in accordance with the polynomial functions. To describe the physical parameters of aluminium, the same data as in experimental tests are used (see below). Then the boundary conditions (the outdoor and indoor air temperatures, as well as air velocities) are determined.

The characteristics of the rotary heat exchanger are introduced by applying the function of porous material. In this case, the porosity of the material $\sigma$, the ratio between the surface area and volume $A / V$ and the heat transfer rate $h_{T}$ are introduced [13].

$$
\begin{gathered}
\sigma=\frac{A_{c}}{A_{M}+A_{c}}, \\
A_{c}=\frac{a^{\prime} b^{\prime}}{2}, \\
a^{\prime}=a-2 s, \\
b^{\prime}=b-2 s, \\
A_{M}=P \frac{s}{2},
\end{gathered}
$$




$$
\begin{gathered}
P=b+2 \sqrt{\left(\frac{b}{2}\right)^{2}+\left(\frac{a}{2} \pi\right)^{2}} \frac{3+\left(\frac{2 b}{\pi a}\right)^{2}}{4+\left(\frac{2 b}{\pi a}\right)^{2}}, \\
\frac{A}{V}=\frac{P L}{\left(A_{c}+A_{M}\right) L}, \\
h_{T}=\frac{N u \cdot k_{a}}{D_{e q}}, \\
\left.+1.9975\left(\frac{a^{\prime}}{b^{\prime}}\right)^{3}-0.4966\left(\frac{a^{\prime}}{b^{\prime}}\right)^{4}\right]^{\prime}, \\
D_{e q}=a^{\prime}\left[1.0542-0.4670 \frac{a^{\prime}}{b^{\prime}}-0.1180\left(\frac{a^{\prime}}{b^{\prime}}\right)^{2}\right. \\
\left.+0.1794\left(\frac{a^{\prime}}{b^{\prime}}\right)^{3}-0.0436\left(\frac{a^{\prime}}{b^{\prime}}\right)^{4}\right]
\end{gathered}
$$

where $\sigma$ is the porosity of the RHE; $s$ is the foil thickness, [m]; $a^{\prime}$ is the internal wave height of the channel, $[\mathrm{m}] ; b^{\prime}$ is the internal width of the channel, $[\mathrm{m}] ; A_{M}$ is the total area of foil cross-section, $\left[\mathrm{m}^{2}\right] ; A_{c}$ is the total area of air channel cross-sections, $\left[\mathrm{m}^{2}\right] ; P$ is the total perimeter of channels, $\left[\mathrm{m}^{2}\right] ; L$ is the length of the RHE, [m]; $A$ is the surface area of foil, $\left[\mathrm{m}^{2}\right] ; V$ is the volume of the RHE, $\left[\mathrm{m}^{3}\right] ; h_{T}$ is the heat transfer coefficient, $\left[\mathrm{Wm}^{-2} \mathrm{~K}^{-1}\right.$; $N u$ is the Nusselt number; $k_{a}$ is the thermal conductivity of air, $\left[\mathrm{Wm}^{-1} \mathrm{~K}^{-1}\right] ; D_{e q}$ is the equivalent diameter of the channel, $[\mathrm{m}]$.

First, the problem is approached in a stationary mode until the air velocity and temperature stabilizes while the rotor is not running. Then the non-stationary mode is activated, and the non-stationary problem of heat transfer is solved. The selected time-step is 0.25 $\mathrm{s}$, while the maximum number of iterations during this time-step is 10 . The process is halted when the variation in the temperature of the supplied air drops below $0.3{ }^{\circ} \mathrm{C}$. This condition is reached within $150 \mathrm{~s}$ to $200 \mathrm{~s}$ of the process simulation, while calculations take $30 \mathrm{~min}$ to $40 \mathrm{~min}$.

\subsection{Calculation of Pressure Loss}

Unlike temperature efficiency, the pressure loss of an RHE can be calculated using the analytical method. Compared to numerical modelling methods, this method saves a significant amount of calculation time.
The calculations were carried out using the following equations [13]:

$$
\begin{gathered}
\Delta p=\xi_{c} \frac{1}{2} \rho u^{2}+4 f \frac{L}{2 D_{e q}} \rho u^{2}, \\
\operatorname{Re}=\frac{u D_{e q}}{\mu} \\
u=\frac{v_{f}}{\sigma}, \\
f R e=9.5687\left[1+0.0772\left(\frac{a^{\prime}}{b^{\prime}}\right)+0.8619\left(\frac{a^{\prime}}{b^{\prime}}\right)^{2}\right. \\
\left.-0.8314\left(\frac{a^{\prime}}{b^{\prime}}\right)^{3}-0.2907\left(\frac{a^{\prime}}{b^{\prime}}\right)^{4}-0.0338\left(\frac{a^{\prime}}{b^{\prime}}\right)^{5}\right],
\end{gathered}
$$

where $\xi_{c}$ is the factor for air expansion and compression at the entrance and exit of the rotor $(0.2) ; \rho$ is the density of air under standard conditions $\left(1.2 \mathrm{kgm}^{-3}\right)$; is the air velocity in the channel; $f$ is the Fanning friction factor; Re is the Reynolds number; $\mu$ is the kinematic viscosity $\left[\mathrm{m}^{2} \mathrm{~s}^{-1}\right] ; v_{f}$ is the air face velocity through the RHE, [ms-1].

\subsection{Calculation of Life Cycle Costs}

The LCC are assumed as the sum of costs of the RHE, electricity consumed in the supply and exhaust air fans, and the heat consumed in the air heating coil, displaced after the RHE in the supply air stream. The lifetime of the RHE is assumed to be equal to the typical lifetime of AHU, which is 10 years.

The cost of the RHE is assumed as the sum of two parts: the cost of manufacturing and the cost of aluminium foil. The manufacturing cost was fixed at 345 EUR, because the same size of all RHEs investigated. The cost of aluminium foil is variable because of the different lengths and porosity of the RHE. The price of aluminium foil was assumed to be 8.62 EUR per kg. The volume of aluminium foil consumed is calculated under Eq. (17):

$$
V=0.25 \pi D^{2} L(1-\sigma) \text {. }
$$

The electrical power and energy consumed in the fans are calculated using the following equations:

$$
\begin{gathered}
P_{e l}=10^{-3} q_{v} \Delta p_{\text {fan }} / \eta_{e}, \\
E_{e l}=\left(P_{e l, s u p}+P_{e l, e x}\right) t_{o p}= \\
=2 \cdot P_{e l} \cdot 10 \cdot 365 \cdot 12 \cdot 5 / 7 .
\end{gathered}
$$

where $q_{v}$ is the volumetric airflow; $\Delta p_{f a n}$ is the pressure difference of the fan, calculated by adding the 200 
$\mathrm{Pa}$ of the ventilation system aerodynamic resistance to the resistance of the RHE obtained from CFD calculations; $\eta_{e}$ is the efficiency of the fan assembly, assumed to be constant and equal to $0.625 ; t_{o p}$ is the annual time of the fan's operation. It is assumed that the ventilation system is used 12 hours per each working day for 10 years.

The heat consumed in the air heat coil is calculated using the following equations and assumptions:

$$
\begin{gathered}
P_{h}=q_{v} \rho c_{p} \max \left(0 ; t_{s a}-t_{s, R H E}-\Delta t_{f a n}\right), \\
t_{s, R H E}=t_{o a}+\eta_{R H E}\left(t_{e a}-t_{o a}\right),
\end{gathered}
$$

where $c_{p}$ is the specific heat of the air $\left(1 \mathrm{~kJ} \mathrm{~kg}^{-1} \mathrm{~K}^{-1}\right)$; $t_{s a}$ is the temperature of the supply air $\left(20^{\circ} \mathrm{C}\right) ; t_{e a}$ is the temperature of the exhaust air $\left(20^{\circ} \mathrm{C}\right) ; t_{o a}$ is the temperature of the outdoor air; $t_{s, R H E}$ is the temperature of the air after the RHE; $\Delta t_{f a n}$ is the increase of the air temperature due to the supply air fan operation $\left(1^{\circ} \mathrm{C}\right)$; $\eta_{R H E}$ is temperature efficiency of the RHE obtained from CFD calculations.

The heat energy calculations were performed for each hour of the ventilation system uptime. The outdoor air temperatures were obtained using RETscreen software [20].

As used for the purposes of the LCC calculations, the price of electricity was 0.099 EUR per $\mathrm{kWh}$, and the price of the heat 0.0463 EUR per kWh.

\subsection{Validation of the Models}

In order to compare the experimental and calculation results, tests with three different condensation rotary heat exchangers were performed at a laboratory located at the factory of KOMFOVENT, a company that specializes in the production of ventilation equipment. Over the course of the testing procedure, the temperature efficiency and pressure loss of the RHE was measured at air speeds between $0.5 \mathrm{~ms}^{-1}$ and $4 \mathrm{~ms}^{-1}$.

The length of every RHE tested was $200 \mathrm{~mm}$ while the diameter was $1,000 \mathrm{~mm}$, the rotational speed was 12 revolutions per minute and the thickness of the foil was $0.065 \mathrm{~mm}$. The characteristics of aluminium foil used were as follows: density of $2,730 \mathrm{kgm}^{-3}$, specific heat capacity of $900 \mathrm{Jkg}^{-1} \mathrm{~K}^{-1}$, thermal conductivity coefficient of $175 \mathrm{Wm}^{-1} \mathrm{~K}^{-1}$. The experiments were carried out under the following conditions: outdoor air temperature of $2{ }^{\circ} \mathrm{C}$, relative humidity of $80 \%$, indoor air temperature of $22{ }^{\circ} \mathrm{C}$, relative humidity of $45 \%$.

As a result, the methodology for calculating the temperature efficiency and pressure loss of a rotary heat exchanger was validated. The comparison of the results for three different cases is provided below; Table 1 shows the following parameters of the heat exchangers under comparison: the air velocity during the test, the wave height, and the wavelength of the foil.

As shown in Table 1, the calculation results are rather similar to the experimental results. In terms of temperature efficiency, the most significant relative difference compared to the experimental result was $2.54 \%$. As for pressure loss, the maximum relative difference was even smaller, only $1.19 \%$.

Minor differences between experimental and calculation results most likely occur due to calculation errors for the wavelength and wave height of the rotary heat exchanger since these parameters vary across the entire area of the rotor.

In addition to these aspects, there might be other reasons that cause the aforementioned differences: the accuracy of the instruments used to measure temperature, the pressure and airflow rate and the excessive sparsity of the finite volume network.

However, a $2.54 \%$ margin of calculation error for temperature efficiency and a $1.19 \%$ margin of calculation error for pressure loss of a rotary heat exchanger constitutes a very good result. This confirms that appropriate methods were selected to determine the temperature efficiency and pressure loss of a rotary heat exchanger.

\section{RESEARCH SCOPE}

In the search for the optimal set of RHE parameters, establishing the scope of research is key since there

Table 1. Results of experiments and calculations

\begin{tabular}{cccccccccccc}
\hline \multicolumn{3}{c}{ Parameters } & \multicolumn{2}{c}{ Experiment } & \multicolumn{2}{c}{ Calculations } & \multicolumn{2}{c}{ Absolute difference } & Relative difference \\
\hline $\begin{array}{c}v, \\
{\left[\mathrm{~ms}^{-1}\right]}\end{array}$ & $\begin{array}{c}a, \\
{[\mathrm{~mm}]}\end{array}$ & $\begin{array}{c}b, \\
{[\mathrm{~mm}]}\end{array}$ & $\begin{array}{c}\text { Temperature } \\
\text { efficiency, [\%] }\end{array}$ & $\begin{array}{c}\text { Pressure } \\
\text { loss, [Pa] }\end{array}$ & $\begin{array}{c}\text { Temperature } \\
\text { efficiency, }[\%]\end{array}$ & $\begin{array}{c}\text { Pressure } \\
\text { loss, [Pa] }\end{array}$ & $\begin{array}{c}\text { Temperature } \\
\text { efficiency, [\%] }\end{array}$ & $\begin{array}{c}\text { Pressure } \\
\text { loss, [Pa] }\end{array}$ & $\begin{array}{c}\text { Temperature } \\
\text { efficiency, [\%] }\end{array}$ & $\begin{array}{c}\text { Pressure } \\
\text { loss, [\%] }\end{array}$ \\
\hline 2.5 & 1.69 & 3.85 & 79.36 & 129.8 & 78.61 & 129.29 & 0.75 & 0.47 & 0.95 & 0.36 \\
\hline 2.5 & 1.39 & 2.60 & 85.17 & 234.0 & 83.01 & 235.22 & 2.16 & -1.22 & 2.54 & -0.52 \\
\hline 1.5 & 1.39 & 4.04 & 84.82 & 102.5 & 82.77 & 103.70 & 2.05 & -1.22 & 2.42 & -1.19 \\
\hline
\end{tabular}


are many variables, and the number of possible combinations thus grows exponentially. The time for calculating temperature efficiency using the ANSYS FLUENT software was reduced as much as possible. The primary calculations took more than 24 hours; however, the time required for the calculations was reduced from $30 \mathrm{~min}$ to $40 \mathrm{~min}$ (computer specifications: i5-5200U CPU @2.2 GHz, 16 GB RAM). This was achieved by shortening the airflow ducts from $3 \mathrm{~m}$ to $1 \mathrm{~m}$, reducing the number of finite volumes from 105,867 to 8,087 , increasing the time-step from $0.05 \mathrm{~s}$ to $0.25 \mathrm{~s}$ and expanding the conditions for the solution from $\Delta t=0.1{ }^{\circ} \mathrm{C}$ to $\Delta t=0.3{ }^{\circ} \mathrm{C}$. The consistency between the calculation results and the experimental data shows (see Table 1) that these changes are acceptable.

The literature review has shown that once the rotational speed of the rotary heat exchanger reaches a certain value, there is virtually no effect on the temperature efficiency [2], [5] and [13]. The results of a large number of studies show that this value does not exceed 12 revolutions per minute. Therefore, in this study, taking into consideration the duration of calculations, the rotational speed of all rotary heat exchangers was pegged at 12 revolutions per minute.

During this study, in search for the optimal set of RHE parameters, air velocity was considered a constant, primarily due to the fact that in almost all the cases of preliminary calculations, the best results were achieved at the lowest air velocity. However, this imposes the largest dimensions of the AHU, which quickly becomes unacceptable from the practical point of view. The analysis of the heat exchangers tested at the KOMFOVENT laboratory showed that the highest temperature efficiency is achieved when the air velocity is about $1.5 \mathrm{~ms}^{-1}$. Therefore, in this study, the air velocity in all analysed rotary heat exchangers was the same: $1.5 \mathrm{~ms}^{-1}$.

Having established the rotational speed and air velocity of the RHE as immutable values, this research focuses on the length of the RHE, the length and width of the foil wave and foil thickness. A matrix of parameter values was made considering the time required for model calculation. These values are provided in Table 2 .

Table 2. Variable parameters of rotary heat exchangers

\begin{tabular}{ccccccc}
\hline Parameter & \multicolumn{7}{c}{ Values of the parameter } \\
\hline$L,[\mathrm{~mm}]$ & 200 & 300 & 400 & - & - & - \\
\hline$s,[\mathrm{~mm}]$ & 0.06 & 0.08 & 0.10 & - & - & - \\
\hline$a,[\mathrm{~mm}]$ & 1.4 & 1.5 & 1.6 & 1.7 & 1.8 & - \\
\hline$b,[\mathrm{~mm}]$ & 2.5 & 3.0 & 3.5 & 4.0 & 4.5 & 5.0 \\
\hline
\end{tabular}

Two hundred and seventy different combinations of rotary heat exchanger parameters were simulated and compared in total. The heat exchangers were compared on the basis of LCC.

\section{RESULTS AND DISCUSSION}

The LCC of different RHE cases are provided below (Fig. 4). A heat exchanger with a length of $400 \mathrm{~mm}$, foil thickness of $0.06 \mathrm{~mm}$, wave height of $1.8 \mathrm{~mm}$, wavelength of $5 \mathrm{~mm}$, pressure loss of $116.5 \mathrm{~Pa}$ and

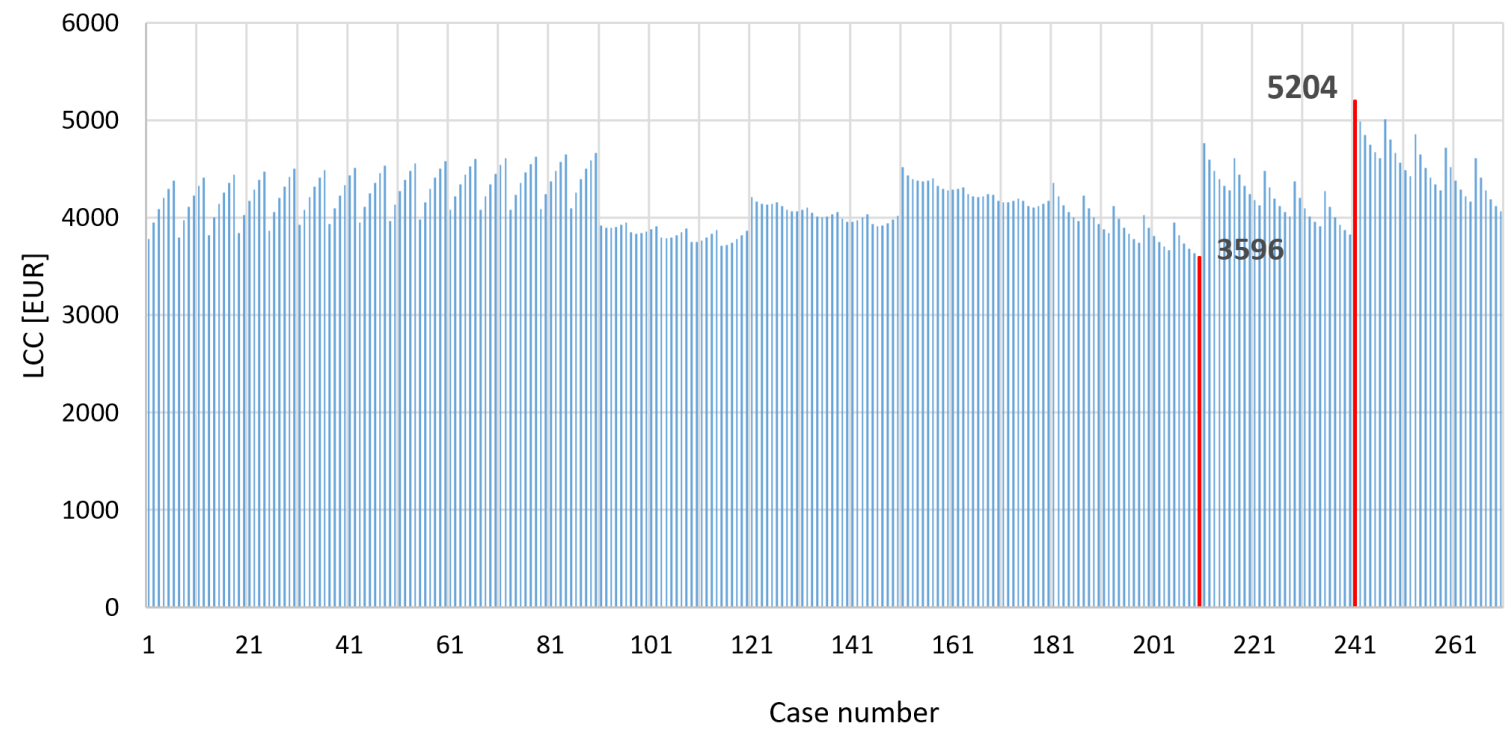

Fig. 4. The life-cycle costs of different rotary heat exchanger options (each vertical line represents a separate case simulated) 
temperature efficiency of $88.2 \%$ produces the lowest lifecycle costs. The lifecycle costs of this kind of heat exchanger are 3,596 EUR over 10 years, i.e., $31 \%$ lower than the heat exchanger with the highest lifecycle costs of 5,204 EUR over 10 years.

As seen in Fig. 5, there is a certain, visually quite obvious correlation $\left(R^{2}=0.50\right)$ between the LCC and temperature efficiency. It can be stated that the lowest LCC is typical of heat exchangers with a temperature efficiency between $85 \%$ and $90 \%$. The figure also shows that both an excessively low and excessively high-temperature efficiency negatively affects the LCC. In this case, when the temperature efficiency is very high, the pressure loss is also significant, leading to increased LCC.

Fig. 6 shows the dependence of the LCC on pressure loss. A quite obvious correlation $\left(R^{2}=0.52\right)$ is evident here as well. In this case, to reduce the

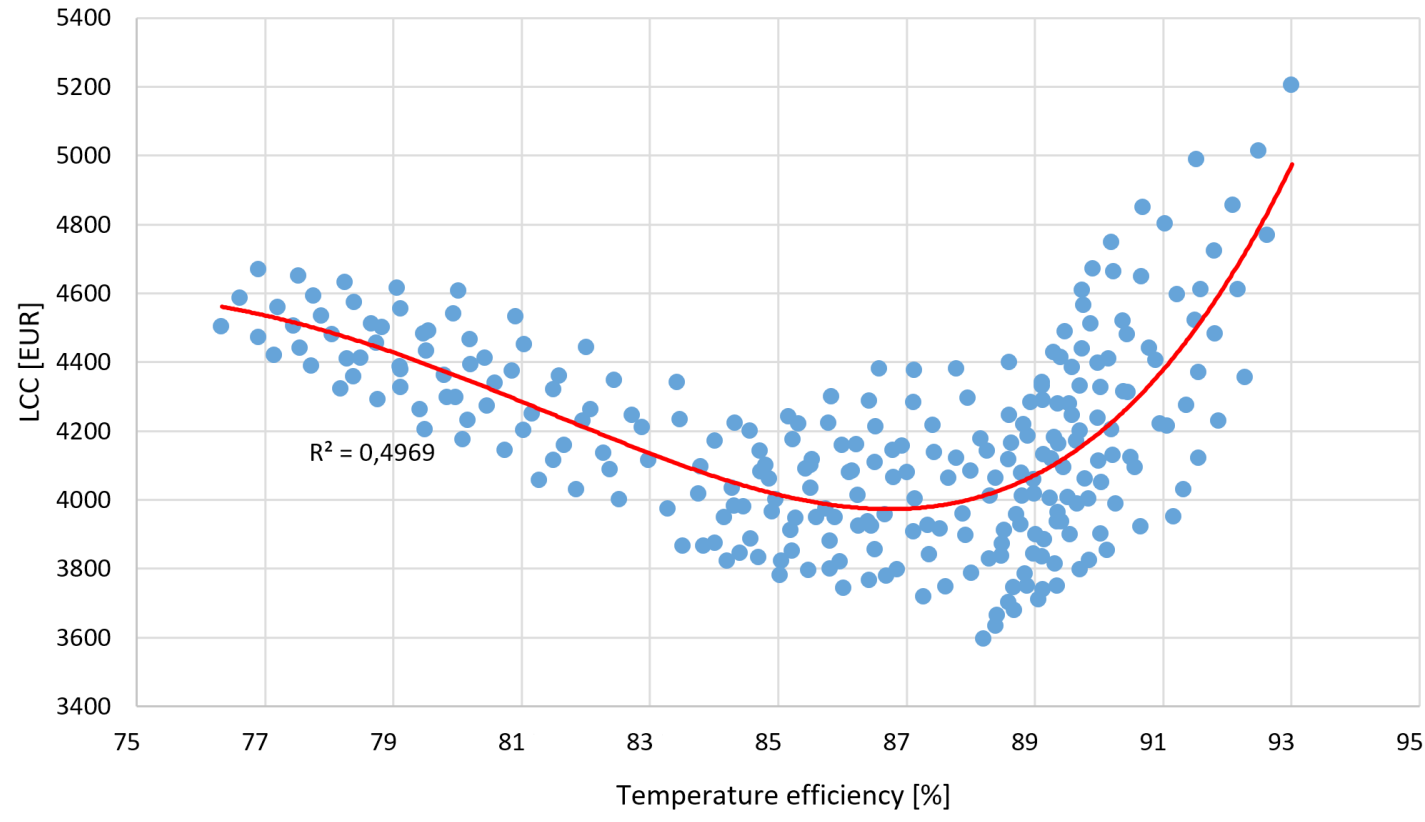

Fig. 5. The dependence of the LCC on temperature efficiency (each dot represents a separate case simulated)

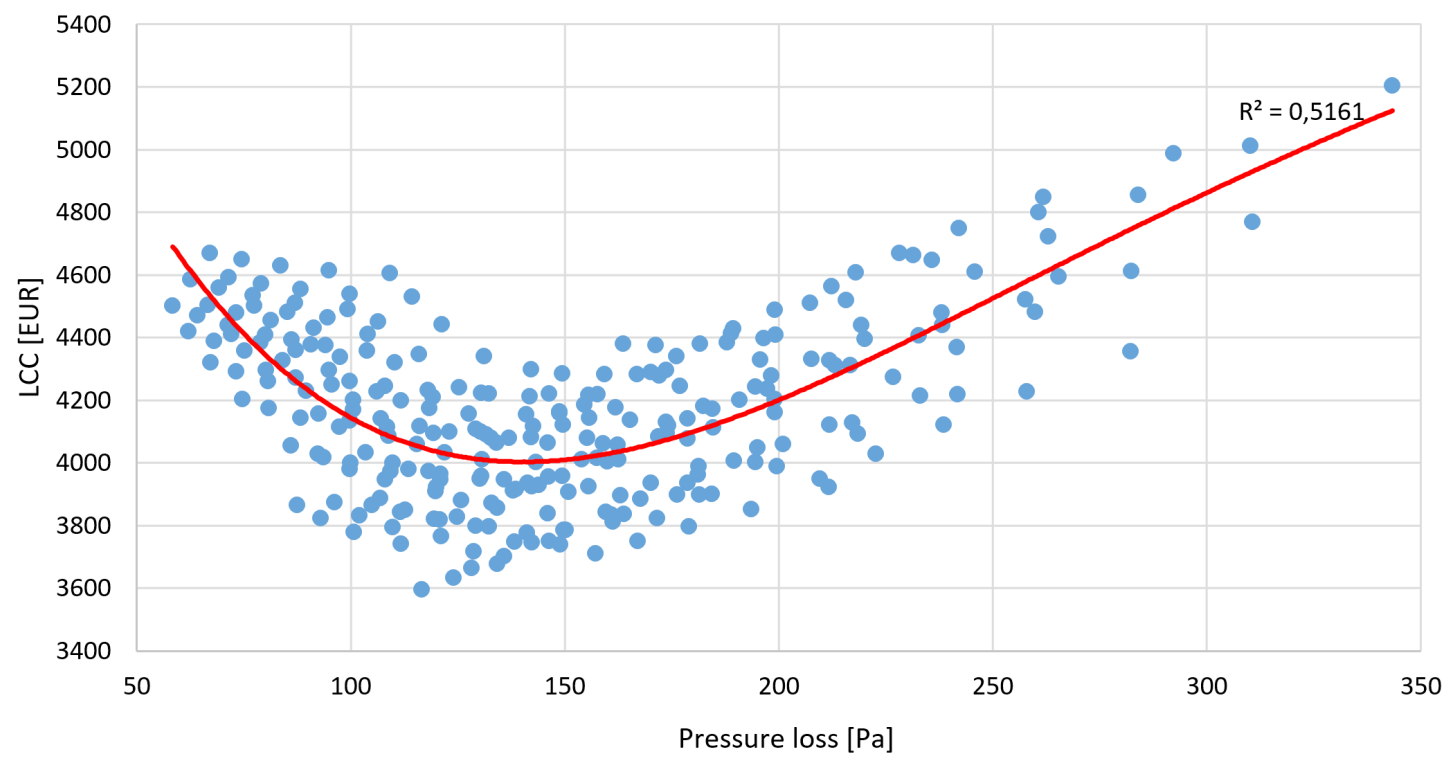

Fig. 6. The dependence of the LCC on pressure loss (each dot represents a separate case simulated) 
LCC, the pressure loss of the heat exchanger should be within $100 \mathrm{~Pa}$ and $200 \mathrm{~Pa}$. This chart, much like the one above, shows that both an excessively low and excessively high-temperature efficiency leads to increased LCC. Pressure loss that is too low leads to lower efficiency, which prevents more significant energy savings, while high-pressure loss leads to increased electricity costs.

In order to determine the optimal parameters of rotary heat exchangers, all heat exchangers with the LCC below the considered limit of EUR 3,800 were analysed (i.e., a total of 22). The length of the first five heat exchangers with the lowest LCC is $400 \mathrm{~mm}$. It should also be noted that the foil thickness of all these heat exchangers is $0.06 \mathrm{~mm}$, which further tightens the limits of the pressure loss that should be taken into consideration when producing a heat exchanger that is the most appealing in terms of the LCC, i.e., $101 \mathrm{~Pa}$ to $179 \mathrm{~Pa}$. In this case, the temperature efficiency of heat exchangers is between $85 \%$ and $90 \%$.

Table 3. Optimal parameters of heat exchangers

\begin{tabular}{cccccc}
\hline $\begin{array}{c}\text { The length } \\
\text { of a RHE } \\
{[\mathrm{mm}]}\end{array}$ & $\begin{array}{c}\text { The number of } \\
\text { heat exchangers of } \\
\text { respective length [-] }\end{array}$ & $\begin{array}{c}b / a \\
{[-]}\end{array}$ & $\begin{array}{c}s \\
{[\mathrm{~mm}]}\end{array}$ & $\begin{array}{c}a \\
{[\mathrm{~mm}]}\end{array}$ & $\begin{array}{c}b \\
{[\mathrm{~mm}]}\end{array}$ \\
\hline 200 & 2 & 1.73 & 0.060 & 1.45 & 2.50 \\
\hline 300 & 11 & 1.86 & 0.060 & 1.71 & 3.18 \\
\hline 400 & 9 & 2.59 & 0.060 & 1.72 & 4.44 \\
\hline
\end{tabular}

Table 3 lists the average parameters of heat exchangers. It becomes evident that the most typical lengths of heat exchangers with the lowest LCC are $300 \mathrm{~mm}$ and $400 \mathrm{~mm}$ (11 and 9 units, respectively). Only two heat exchangers are $200 \mathrm{~mm}$ long. The table also shows that the foil of these heat exchangers is the thinnest out of those analysed in this study: $0.06 \mathrm{~mm}$. The average ratio of wavelength to wave height, in this case, is $1.73,1.86$, and 2.59 for the heat exchangers with the length of $200 \mathrm{~mm}, 300 \mathrm{~mm}$, and $400 \mathrm{~mm}$, respectively. The average wave height of heat exchangers that are the most appealing in terms of the LCC is $1.45 \mathrm{~mm}$ (for $200 \mathrm{~mm}$ heat exchangers), 1.71 $\mathrm{mm}$ (for $300 \mathrm{~mm}$ heat exchangers), and $1.72 \mathrm{~mm}$ (for $400 \mathrm{~mm}$ heat exchangers). The average wavelength of heat exchangers is $2.50 \mathrm{~mm}$ for $200 \mathrm{~mm}, 3.18 \mathrm{~mm}$ for $300 \mathrm{~mm}$, and $4.44 \mathrm{~mm}$ for $400 \mathrm{~mm}$.

Neither the wave height and wavelength nor the ratio of the two have been observed to have any impact. This can be explained by the narrow gauge of the air channels. While they are narrow enough to keep the physical proprieties of the air stream homogenous in the same cross-section, the shape of the air channel's cross-section makes no difference.
Obviously, the total foil surface area exposed to the air has a much greater influence. This parameter affects the RHE's temperature efficiency and its pressure drop.

\section{CONCLUSIONS}

1. The literature review reveals a lack of specific recommendations for the constructional parameters of rotary heat exchangers. Most research projects focus on simulating heat and mass transfer processes and on improving the efficiency of these processes. There is also a lack of discussion about the criteria of rotary heat exchanger optimization. Most cases only refer to the efficiency of heat and moisture recovery as a criterion.

2. Good coherence of the calculation results and laboratory tests made at the KONFOVENT laboratory proves the suitability of the CFD model for the calculation of the temperature efficiency of rotary heat exchanger described. These tests also prove the suitability of the analytical model presented in [13] for the calculation of pressure drop of a rotary heat exchanger.

3. The lifecycle costs analysis of 270 different RHE variants calculated using the CFD and analytical models has shown that the best results are achieved when the length of the rotary heat exchanger is maximal $(400 \mathrm{~mm}$ in the cases analysed), foil thickness is minimal $(0.06 \mathrm{~mm}$ in the cases analysed), and pressure loss is between $100 \mathrm{~Pa}$ and $180 \mathrm{~Pa}$. The temperature efficiency of an RHE in cold climate conditions, in this case, is expected to be between $85 \%$ and $90 \%$.

4. This research confirms that it does not take the best heat recovery efficiency to achieve the best energy efficiency of a rotary heat exchanger due to its pressure loss. The difference between the heat exchangers with the lowest LCC and the heat exchangers with the highest LCC can reach 31 $\%$ in the same weather and economic conditions; this difference depends mainly on the geometrical characteristics of the rotary heat exchanger.

\section{REFERENCES}

[1] ElA (2012). Commercial Buildings Energy Consumption Survey: Energy Usage Summary., from https://www.eia.gov/ consumption/commercial/reports/2012/energyusage/, accessed on 2021-01-22.

[2] Al-Ghamdi, A.S. (2006). Analysis of Air-to-Air Rotary Energy Wheels, PhD Thesis, Ohio University, Ohio. 
[3] Grzebielec, A., Rusowicz, A., Rucinski, A. (2014). Analysis of the performance of the rotary heat exchanger in the real ventilation systems, The 9th International Conference Environmental Engineering, D0I:10.3846/enviro.2014.259.

[4] Kang, H., Lee, G., Lee, D.-Y. (2015). Explicit analytic solution for heat and mass transfer in a desiccant wheel using a simplified model. Energy, 93, p. 2559-2567, D0l:10.1016/j. energy.2015.10.091.

[5] Sanaye, S., Jafari, S., Ghaebi, H. (2008). Optimum operational conditions of a rotary regenerator using genetic algorithm. Energy and Buildings, vol. 40, no. 9, p. 1637-1642, DOI:10.1016/j.enbuild.2008.02.025.

[6] Park, B., Lee, S. (2020). Investigation on heat and mass transfer characteristics for a zeolite-coated heat exchanger using comparatively low-temperature energy: heating humidification mode and cooling dehumidification mode. Indoor and Built Environment, p. 1-17, in press, DOI:10.1177/1420326X20942291.

[7] Eurovent (2021). Air to Air Rotary Heat Exchangers. Certification Programme, Eurovent, Paris.

[8] Kanaś, P., Jedlikowski, A., Anisimov, S. (2019). the influence of geometrical parameters on heat and mass transfer processes in rotary heat exchangers. SN Applied Sciences, vol. 1, art ID 526, Dol:10.1007/s42452-019-0540-2.

[9] Merzkirch, A., Maas, S., Scholzen, F., Waldmann, D. (2016). Field tests of centralized and decentralized ventilation units in residential buildings - specific fan power, heat recovery efficiency, shortcuts and volume flow unbalances, Energy and Buildings, vol. 116, p. 376-383, D0l:10.1016/j. enbuild.2015.12.008.

[10] Dodoo, A. (2020). Primary energy and economic implications of ventilation heat recovery for a multi-family building in a nordic climate. Journal of Building Engineering, vol. 31, art. ID 101391, D0I:10.1016/j.jobe.2020.101391.

[11] Mok, S., Kumar, S., Hutchins, R.R., Joshi, Y.K. (2016). Impact of a rotary regenerative heat exchanger on energy efficiency of an air cooled data center. 15th IEEE Intersociety Conference on Thermal and Thermomechanical Phenomena in Electronic Systems, p. 1182-1190, D0l:10.1109/ITHERM.2016.7517682.
[12] Wang, L., Bu, Y., Chen, X., Wei, X., Li, D., Che, D. (2018). Multiobjective design optimization of rotating regenerative air preheater using genetic algorithm. Proceedings of the ASME Power Conference with ASME $12^{\text {th }}$ International Conference on Energy Sustainability and ASME Nuclear Forum. DOI:10.1115/POWER2018-7417.

[13] De Antonellis, S., Intini, M., Joppolo, C.M., Leone, C. (2014). Design optimization of heat wheels for energy recovery in HVAC systems. Energies, vol. 7, no. 11, p. 7348-7367, DOI:10.3390/en7117348.

[14] Mioralli, P.C., Da Silva, M.A.B., Avallone, E., Palota, P.H., Natividade, P.S.G. (2019). Computational analysis for good thermal exchange and low pressure drop in regenerative air preheaters. Journal of Energy Research and Reviews, vol. 2, no. 4, p. 1-15, D0l:10.9734/jenrr/2019/v2i430083.

[15] Fathieh, F., Besant, R.W., Evitts, R.W., Simonson, C.J. (2015). Determination of air-to-air heat wheel sensible effectiveness using temperature step change data. International Journal of Heat and Mass Transfer, vol. 87, p. 312-326, D0l:10.1016/j. ijheatmasstransfer.2015.04.028.

[16] Yilmaz, T., Büyükalaca, 0. (2003). Design of regenerative heat exchangers. Heat Transfer Engineering, vol. 24, no. 4, p. 32 38, D0I:10.1080/01457630304034.

[17] Zendehboudi, A. (2016). Implementation of GA-LSSVM modelling approach for estimating the performance of solid desiccant wheels. Energy Conversion and Management, vol. 127, p. 245-255, D0l:10.1016/j.enconman.2016.08.070.

[18] Rashidi, S., Kashefi, M.H., Kim, K.C., Samimi-Abianeh, 0. (2019). Potentials of porous materials for energy management in heat exchangers - A comprehensive review. Applied Energy, vol. 243, p. 206-232, D0l:10.1016/j.apenergy.2019.03.200.

[19] Ansys Fluent | Fluid Simulation Software (2021). from https:// www.ansys.com/products/fluids/ansys-fluent, accessed on 2021-05-03.

[20] Government of Canada, (2010). Retscreen. Clean Energy Management Software, from https://www.nrcan.gc.ca/mapstools-and-publications/tools/modelling-tools/retscreen/7465, accessed on 2021-05-03. 